Article

\title{
Cryptosporidium Oocysts Removal by Upflow Direct Filtration: Pilot Scale Assessment
}

\author{
Marcely Ferreira Nascimento ${ }^{1}$, Yovanka Pérez Ginoris ${ }^{2}$ and Cristina Celia Silveira Brandão ${ }^{2, *}$ (]) \\ 1 Instituto Federal do Triângulo Mineiro, Fazenda Sobradinho, Uberaba CEP 38400-974, Brazil; \\ marcely@iftm.edu.br \\ 2 Department of Civil and Environmental Engineering, University of Brasilia, \\ Brasilia CEP 70910-900, Distrito Federal, Brazil; yovanka@unb.br \\ * Correspondence: cbrandao@unb.br; Tel.: +55-61-981519913
}

Received: 1 March 2020; Accepted: 22 April 2020; Published: 8 May 2020

check for updates

\begin{abstract}
Studies on the removal of Cryptosporidium oocysts by direct filtration suggested that high removal efficiencies $(>3.0 \mathrm{log}$ ) can be achieved, but the vast majority of the studies focused on the assessment of downflow direct filtration. However, in comparison with downflow direct filtration, filters in upflow direct filtration systems use lower filtration rates, deeper stratified bed, and water flows from coarse to fine sand grain, which may improve the removal of oocysts. In this context, we evaluated the removal of Cryptosporidium oocysts using upflow direct filtration, on a pilot scale, to treat Paranoá Lake water (Brazil) seeded with Cryptosporidium oocysts. The experiments were conducted with raw water with low turbidity (3.2-5.7 NTU) and induced higher turbidity (28-30 NTU). Non-parametric statistical analysis was used to verify correlations between the filtered water values and removal of oocysts, particles, and turbidity. In general, no correlation was observed between the parameters analyzed, nor between their removals. The exception was the correlation between residual values of Cryptosporidium oocysts and particles of 2 to $7 \mu \mathrm{m}$ during ripening, an aspect that needs further evaluation. Under stable operation, average removal of Cryptosporidium oocysts by upflow direct filtration was $>3.87 \mathrm{log}$. During ripening, removal of oocysts was around $1 \log$ lower.
\end{abstract}

Keywords: Cryptosporidium oocysts; particle counts; turbidity; upflow direct filtration

\section{Introduction}

The absence and deficiency of water and sanitation infrastructure and services in different regions of Brazil represents a continuous public health risk. This problem has intensified due to the increase in population in the country's urban areas, industrialization, and accelerated land occupation, leading to a deterioration of water resources and increasing risk of waterborne diseases, including those caused by intestinal protozoa that are resistant to chlorination, which is the disinfection process commonly used in Brazil.

Cryptosporidium transmission occurs by untreated surface water, improper water treatment or water contaminated in distribution systems. Previous studies have demonstrated the occurrence of Cryptosporidium oocysts in several regions of Brazil and in different environments, such as groundwater, surface water, drinking water systems, both in untreated raw water (influent) and treated finished water, as well as wastewater [1-7]. In this context, concerns regarding the risk associated with Cryptosporidium spp. have led the Ministry of Health to enforce, through ordinance 2914/2011 (reedited as Annex XX of Ordinance 5/2017 [8]), regulation for filtered water produced by conventional or direct filtration, where turbidity must be less than or equal to 0.5 NTU in at least $95 \%$ of the samples. Moreover, turbidity values must be less than or equal to 0.3 NTU in filtered water when 
the concentration of Cryptosporidium spp. oocysts in the source water is equal to or greater than 3.0 oocysts/L.

Cryptosporidium oocysts are resistant to environmental stress and to inactivation by chlorine [9]. Due to the small oocyst size, filtration is considered an essential barrier in water treatment plants for reducing risks to human health associated with this pathogen. Therefore, despite the development of disinfection technologies capable of achieving reasonable levels of Cryptosporidium oocysts inactivation, traditional physicochemical technologies remain important tools for achieving desirable removal levels of this pathogen.

In Brazil, although conventional treatment is still the most widely used method, the use of direct filtration systems has increased due to the lower implementation costs of these technologies. According to Di Bernardo et al. [10], in the beginning of the 21st century over 350 water treatment plants in Brazil used upflow direct filtration, with capacities of 5 to $2000 \mathrm{~L} / \mathrm{s}$, and the use of the direct filtration process has already exceeded conventional treatment in various states of the country. The 2008 national survey on water and sanitation [11] revealed that, daily, around 4 million cubic meters of water are treated using non-conventional techniques and over 13 million cubic meters of the water distributed to the population is only disinfected, mostly with chlorine. So, direct filtration may play an important role in producing safe water in Brazil.

Studies on the removal of Cryptosporidium oocysts by direct filtration have suggested that, with efficient coagulation and stable operation, high removal efficiencies $(>3.0 \log )$ can be obtained [12-18]. Most of the research on the removal of Cryptosporidium oocysts by direct filtration has assessed downflow direct filtration.

In this context, how upflow direct filtration systems behave with the occurrence of Cryptosporidium oocysts in raw water must be assessed. According the Brazilian Society of Technical Standards (ABNT) [19], if it is not possible to conduct pilot plant filtration experiments, upflow filters must be designed to operate with filtration rates up to $5 \mathrm{~m} / \mathrm{h}$, using deep stratified bed ( $\geq 2 \mathrm{~m}$ ) with water flowing from coarse- to fine-sand grain. These design characteristics may positively influence on the removal of Cryptosporidium oocysts.

In this study, we evaluated the removal of Cryptosporidium oocysts using the upflow direct filtration process (coagulation + filtration), by performing experiments on a pilot scale. The evaluation considered the removal efficiency during the beginning of the filtration run (ripening) as well as during stable filtration. Non-parametric statistical techniques were used to verify correlation between the filtered water turbidity, particle counts and Cryptosporidium oocysts and their removal.

\section{Materials and Methods}

Pilot-scale investigations were performed with source water collected from Lake Paranoá (Brasilia-Federal District, Brazil). Paranoá lake water, in the point of withdrawal, is typically 20 to $27{ }^{\circ} \mathrm{C}$, turbidity $<10 \mathrm{NTU}$, true color $<15 \mathrm{HU}$, alkalinity $<30 \mathrm{mg} \mathrm{CaCO} / \mathrm{L}, \mathrm{pH}$ from 6.0 to 7.3 and dissolved organic carbon $<1.5 \mathrm{mg} / \mathrm{L}$ - characteristics that are compatible with the upflow direct filtration [10]. Paranoá Lake water was seeded with inactivated Cryptosporidium paroum oocysts supplied by the School of Medicine at Triângulo Mineiro (Minas Gerais State, Brazil) to create the raw water (RW) to be used in filtration experiments. Concentration of Cryptosporidium oocysts in the seeded raw water ranged from $10^{2}$ to $10^{3}$ oocysts/L. The high initial concentration of Cryptosporidium oocysts in the raw water is a strategy used in various studies $[12,13,20]$ to ensure detection in the filtered water and allow evaluation of the removal efficiency.

Before the filtration experiments, jar tests, adapted for direct filtration according to a routine described elsewhere [10], were carried out using alum as the coagulant. With Paranoá Lake water (turbidity $=2.7$ to $4.8 \mathrm{NTU}$ ), alum doses from 0 to $14 \mathrm{mg}$ of $\mathrm{Al}_{2}\left(\mathrm{SO}_{4}\right)_{3} / \mathrm{L}$ were tested. However, when Paranoá Lake water was spiked with kaolinite to induce higher turbidity (approximately $30 \mathrm{NTU})$, the doses tested ranged from 12 to $22 \mathrm{mg} \mathrm{Al}_{2}\left(\mathrm{SO}_{4}\right)_{3} / \mathrm{L}$. The coagulation pH ranged from 5.0 to 7.5. The data obtained in the jar tests were used to plot turbidity removal isovalue lines, with $\mathrm{pH}$ 
coagulation on the $\mathrm{X}$ axis, coagulant dose on $\mathrm{Y}$ axis and turbidity removal (after filtration) on the $\mathrm{Z}$ axis. The coagulation conditions ( $\mathrm{pH}$ and optimal dose) were selected based on higher removal regions in these graphics.

\subsection{Pilot Plant Apparatus}

The upflow direct filtration experiments were conducted in a pilot plant. The upflow pilot filter had a total height of $4.0 \mathrm{~m}$ with sand medium depth of $1.86 \mathrm{~m}$ over a $0.85 \mathrm{~m}$ support layer. The sand medium consisted of four sub-layers with the granulometric characteristics proposed by Sens et al. [21] (Figure 1).

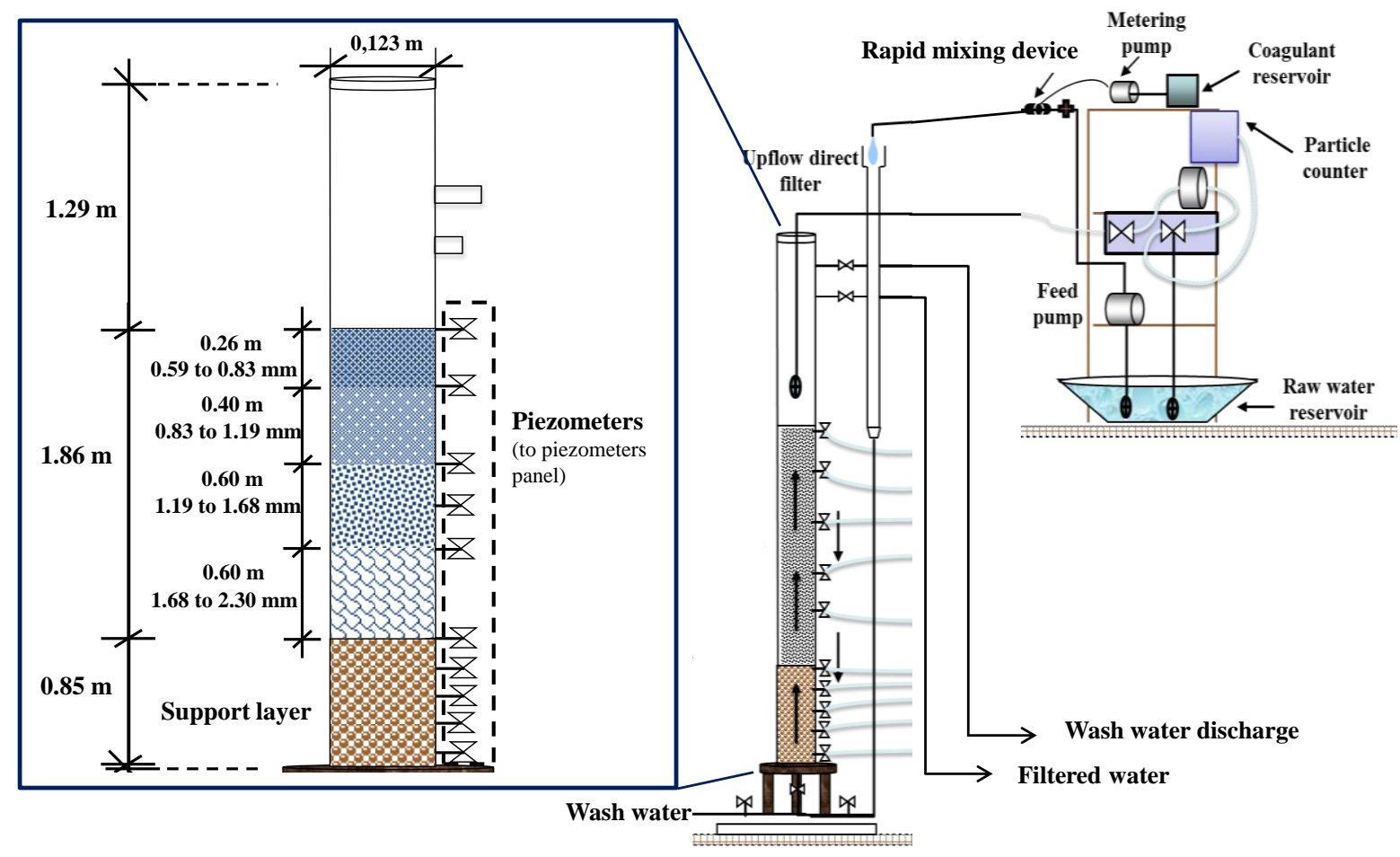

Figure 1. Schematics of pilot-scale upflow direct filtration plant (not in scale).

The filter was operated at constant filtration rate of $5 \mathrm{~m} / \mathrm{h}$. Flow rate was measured volumetrically and pressure losses were monitored using piezometers. Twelve filtration experiments were performed: nine with low turbidity raw water and three with induced higher turbidity raw water. After each experiment, the filtration medium was washed with pumped tap water during 20 min at $30 \%$ medium expansion (upflow velocity around $85 \mathrm{~m} / \mathrm{h}$ ).

Considering the objective of the study, evaluation of the filter during ripening and stable operation, the filtration experiments were stopped after 6 to $7 \mathrm{~h}$ of filter operation. Thus, within the stable operation period.

\subsection{Sampling and Analysis}

During filtration experiments $\mathrm{pH}$ (pHmeter Orion 210, Thermo Fisher Scientific, Waltham, MA, USA), turbidity (HACH 2100 AN, Loveland, CO, USA), total coliforms and Escherichia coli (Colilert), as well as Cryptosporidium oocysts, were monitored in both raw and filtered water. Coagulated water samples were also analyzed to check the coagulation $\mathrm{pH}$. During filter operation, $\mathrm{pH}$, and turbidity were monitored every $15 \mathrm{~min}$ during the first hour and every $30 \mathrm{~min}$ in the following hours. Samples for coliform and Cryptosporidium oocysts analysis (using the USEPA method 1623 [22]) were collected at the beginning of filtration run (ripening period) and after around $6 \mathrm{~h}$ of operation (stable period). For quantification of oocysts, a 1 L composite sample of the water from the raw water reservoir was 
collected during the experiment; the samples of filtered water were collected during ripening period and stable operation taking about $30 \mathrm{~min}$, with a sample volume of $30 \mathrm{~L}$. The first sample of filtered water was collected after the remaining wash water in the filter was displaced by the water being treated. The time necessary for displacement of the wash water, $23 \mathrm{~min}$, was determined experimentally using of a tracer.

In eight experiments, particle size distribution, both in raw and filtered water, were monitored using an on-line particle counter (Hach, model 2200 PCX, Loveland, CO, USA). The particle counter was set to size particles into 21 bins, varying from 2 to $70 \mu \mathrm{m}$.

\subsection{Statistical Analysis}

Data on particle counts, turbidity, and Cryptosporidium oocysts levels in raw and filtered water were recorded during the filtration experiments and treated to obtain their descriptive statistics, mainly the average and standard deviation. Non-parametric statistical techniques were applied to determine the existence of statistically significant correlations between the parameters and the removals in log units. Spearman's non-parametric correlation test was applied with variation between -1 and 1 using Version 9.0 of the Statistica StatSoft software. Non-parametric statistics represent a set of techniques most appropriate for use in studies where the distribution of a population and its parameters are not well known. Box-whisker plots of log removals were also produced.

\section{Results and Discussion}

During the period when the upflow direct filtration experiments were conducted, Paranoá Lake water turbidity, total coliforms and E. coli varied from 2.7 to $4.8 \mathrm{NTU}$, from $1.46 \times 10^{3}$ to $3.85 \times 10^{4} \mathrm{MPN} / 100 \mathrm{~mL}$ and from not detected to $1.83 \times 10^{3} \mathrm{MPN} / 100 \mathrm{~mL}$, respectively. $\mathrm{pH}$ values ranged from 6.0 to 6.9. Paranoá Lake water has low turbidity values, even in the rainy season, and its turbidity is largely associated with the presence of algae.

\subsection{Turbidity and Cryptosporidium Oocysts}

Cryptosporidium oocysts data from upflow filtration experiments are shown in Figure 2. Table 1 summarizes the average of turbidity, turbidity removal and Cryptosporidium oocysts removal obtained during filtration experiments. As can be seen in Table 1, experiments E1 to E9 were conducted with low turbidity raw water (3.2 to $5.7 \mathrm{NTU}$ ) and experiments E10 to E12 were performed with higher turbidity (kaolinite spiked) water to evaluate filtration efficiency under turbidity level near the threshold recommended by Di Bernardo et al. [10] for the use of upflow direct filtration.

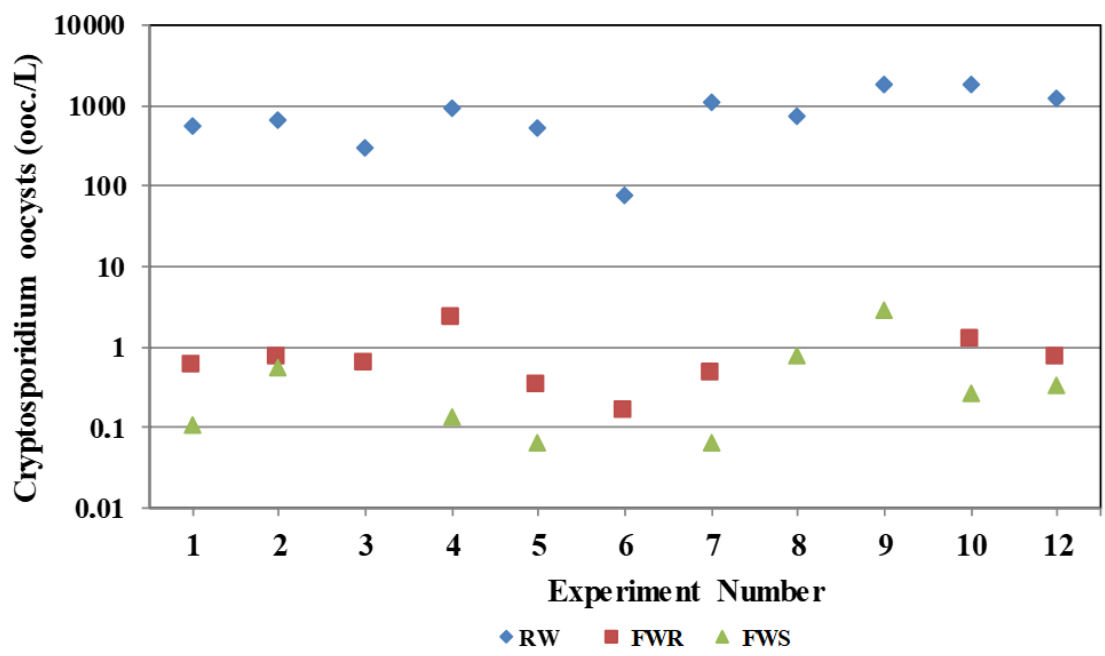

Figure 2. Cryptosporidium oocysts in raw and filtered water (RW-Raw Water; FWR-filtered water during ripening; FWS—filtered water during stable operation). 
Table 1. Turbidity and Cryptosporidium oocysts values and log removals in the upflow direct filtration experiments.

\begin{tabular}{|c|c|c|c|c|c|c|c|c|c|}
\hline \multirow{3}{*}{$\begin{array}{l}\text { Experiment } \\
\text { Number }\end{array}$} & \multicolumn{6}{|c|}{ Turbidity } & \multirow{3}{*}{$\begin{array}{l}\text { Oocysts } \\
\text { RW } \\
\text { (ooc./L) }\end{array}$} & \multirow{2}{*}{\multicolumn{2}{|c|}{$\begin{array}{c}\text { Oocysts } \\
\text { Removal } \\
(\log )\end{array}$}} \\
\hline & \multirow{2}{*}{$\begin{array}{c}\text { Observations } \\
\text { (N) }\end{array}$} & \multirow{2}{*}{$\begin{array}{c}\begin{array}{c}\text { RW } \\
\text { (NTU) }\end{array} \\
\text { Mean }\end{array}$} & \multicolumn{2}{|c|}{$\begin{array}{l}\text { Residual-FW } \\
\text { (NTU) }\end{array}$} & \multicolumn{2}{|c|}{$\begin{array}{l}\text { Removal } \\
(\log )\end{array}$} & & & \\
\hline & & & Mean & SD & FWR & FWS & & FWR & FWS \\
\hline E1 & 15 & 4.8 & 0.27 & 0.14 & 1.20 & 1.24 & 565 & 2.98 & 3.70 \\
\hline E2 & 17 & 5.7 & 0.28 & 0.14 & 1.15 & 1.31 & 674 & 2.96 & 3.10 \\
\hline E3 & 17 & 5.4 & 0.32 & 0.06 & 1.06 & 1.22 & 292 & 2.62 & $>4.20$ \\
\hline E4 & 17 & 4.4 & 0.31 & 0.11 & 1.25 & 1.15 & 902 & 2.60 & 3.80 \\
\hline E5 & 17 & 5.0 & 0.27 & 0.03 & 1.16 & 1.26 & 522 & 3.19 & 3.90 \\
\hline E6 & 17 & 3.5 & 0.25 & 0.04 & 1.05 & 1.14 & 76 & 2.68 & $>4.20$ \\
\hline E7 & 16 & 5.4 & 0.21 & 0.03 & 1.15 & 1.40 & 1122 & 3.37 & 4.20 \\
\hline E8 & 14 & 4.4 & 0.18 & 0.06 & 1.10 & 1.42 & 752 & $(*)$ & 3.00 \\
\hline E9 & 15 & 3.2 & 0.16 & 0.01 & 1.18 & 1.30 & 1864 & $(*)$ & 2.80 \\
\hline E10 & 18 & 28 & 0.32 & 0.03 & 1.81 & 1.93 & 1796 & 3.18 & 3.80 \\
\hline E11 & 17 & 30 & 0.43 & 0.30 & 1.07 & 1.85 & $(* *)$ & $(* *)$ & $(* *)$ \\
\hline E12 & 17 & 30 & 0.22 & 0.04 & 2.09 & 2.13 & 1246 & 3.24 & 3.60 \\
\hline
\end{tabular}

RW-Raw Water; FW—filtered water; FWR—filtered water during ripening; FWS-filtered water during stable operation; SD—Standard Deviation; $\left({ }^{*}\right)$ no sample collected for Cryptosporidium oocysts detection; $\left({ }^{* *}\right)$ filtration experiment without seeded Cryptosporidium oocysts.

Figure 2 shows that in the experiments with data of Cryptosporidium oocysts in both filtered water during ripening period and during stable operation (E1 to E7, E10, and E12), the quantification of oocysts in filtered water during stable operation (FWS) was slightly lower. Mann-Whitney's nonparametric test indicated that such differences were statistically significant at a $95 \%$ confidence $(p$ value $=0.0009)$, indicating the filter's vulnerability in the early stages of filtration run. Filters vulnerability during ripening period was also observed by other researchers who evaluated the efficiency filtration on Cryptosporidium oocysts removal [13,23-25].

The Cryptosporidium oocysts removal data presented in Table 1 point out the difference in the performance of the filter during ripening period and during stable operation. Although the large range of removal in both ripening and stable operation, log removal under these operational conditions was statistically different at a 95\% confidence level ( $p$ value $<0.0001$, Mann-Whitney).

For experiments E1 to E7, carried out with low turbidity water, the average Cryptosporidium oocysts removal was $2.91 \mathrm{log}$ during ripening and was $>3.87$ under stable operation. Therefore, the decrease in oocysts removal was near $1 \mathrm{log}$. This value is higher than those reported by Huck et al. [23] and Emelko [13], but it is in the range of 0.5 to $1 \log$ reported by these authors based on other works [24,26].

According to O'Melia and Aly [27], "particles retained in a packed-bed filter during the initial stages of a run can act as collectors for other suspended particles applied to the bed at late time". Those collectors provide additional sites for further removal, and due to coagulation, they have surface charges that favor attachment forces, and higher retention during stable operation is expected. So, the higher passage of Cryptosporidium oocysts observed during ripening in this work is thought to be the result of the poor retention of the coagulated particles (including oocysts) on the surface of the cleaned grains in the early stage of operation, and was not influenced by the effect of the particles in wash water remnants due to the wash procedure carried out between the filtration experiments (20 $\mathrm{min}$ at $30 \%$ medium expansion) and the interval before collecting the first sample.

During stable operation, removal of Cryptosporidium oocysts was in the range of 2.80 to $>4.20 \mathrm{log}$, which is consistent with USEPA credit of $2.5 \log$ for direct filtration [28] as well as the values reported in various studies summarized by Emelko et al. [26], and others after that [15-18].

As can be seen in Table 1 and Figure 3, the removal of turbidity was lower during the ripening period than during stable operation, similar to Cryptosporidium oocysts removal. Despite this, no statistical correlation between removal of turbidity and removal of Cryptosporidium oocysts was observed, or 
between residual turbidity and residual of Cryptosporidium oocysts. The lack of correlation is in agreement with other studies [20,24,25,29]. In this work (Figure 3), turbidity removal was consistently lower than Cryptosporidium oocysts removal in both ripening and stable operation of the upflow filter, suggesting that turbidity removal may be a conservative indicator for Cryptosporidium oocysts removal, as previously reported in the literature [30,31].

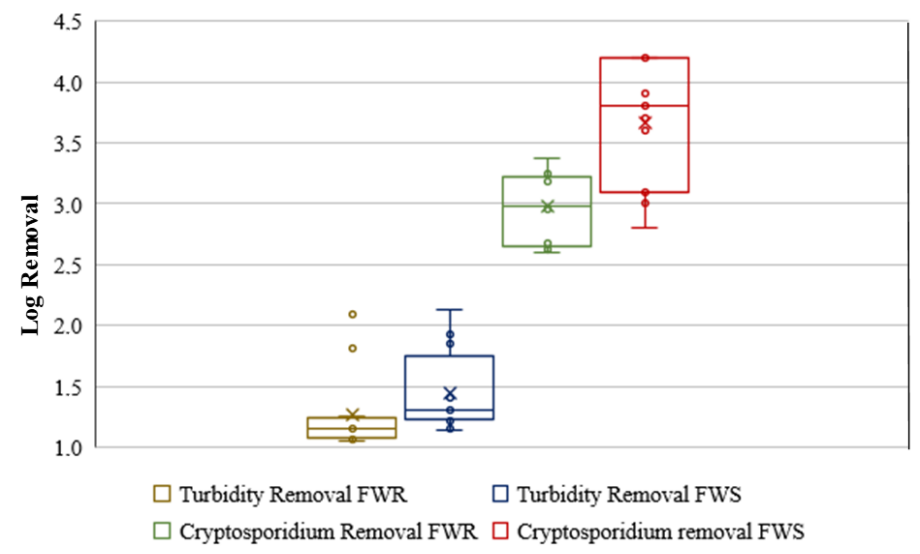

Figure 3. Comparative log removal of turbidity and of Cryptosporidium oocyst during ripening (FWR) and during stable operation (FWS).

Comparing data obtained in this study with previous results of the same group [32], that evaluated downflow direct filtration (bed depth-1.1 m; sand; effective size-1 mm; uniformity coefficient-1.15; filtration rate- $8.75 \mathrm{~m} / \mathrm{h}$ ) and similar raw water (Paranoá Lake water seeded with C. parvum inactivated oocysts), the upflow direct filtration provided an average Cryptosporidium oocysts removal of more than $1.5 \log$ higher. Both filters were operated at optimal coagulation conditions and similar flow rate.

The better result obtained with the upflow direct filtration was expected due to the differences in the design and operation of the filters. Considering the filtration rates (upflow, $5 \mathrm{~m} / \mathrm{h}$; downflow, $8.75 \mathrm{~m} / \mathrm{h}$ ) and the necessary surface filter area (cross section) for each pilot filter when treating the same flow rate, in $\mathrm{m}^{3} / \mathrm{h}$, the deeper upflow filter provided more attachment sites (total surface area of grains more than twice of the downflow) which, together with the lower filtration rate, provided more retention of particles, including Cryptosporidium oocysts. The beneficial effect of a deeper bed (more attachment sites) was reported by Liu et al. [33] and agrees with filtration theory.

Another advantage of the upflow filter that became clear in the comparison with the downflow filter was the head loss development. Whereas the downflow filter head loss reached $1.8 \mathrm{~m}$ before $5 \mathrm{~h}$ of operation, the upflow filter head loss in the same period was always less than $0.3 \mathrm{~m}$, regardless of the influent turbidity. Considering the filtration rates and respectively pilot filters surface areas, in $5 \mathrm{~h}$ of operation both filters, downflow and upflow, produced around $300 \mathrm{~L}$ of filtered water.

This comparison suggests that, considering the differences in design, upflow direct filtration may be a more robust option to downflow direct filtration for treating low turbidity water with Cryptosporidium oocysts.

\subsection{Particle Counts and Cryptosporidium Oocysts}

Due to the difficulty associated with the direct detection of Cryptosporidium oocysts, besides the turbidity measurements, particle counting is a parameter that has been investigated in several studies as surrogate measure for oocysts removal in water treatment systems $[14,15,20,24,34,35]$. Generally, previous research reported discrepancies regarding the existence of correlations between particle counts and Cryptosporidium oocysts removals.

Le Chevallier and Norton [34] combined data from four water supply systems, representing three watersheds with different turbidity levels (low, moderate, and high turbidity) of raw water, treated at conventional water treatment plants. The authors found a good correlation $(r=0.83, p<0.05)$ 
between Cryptosporidium oocysts removal and the number of particles larger than $5 \mu \mathrm{m}$. Nieminski and Ongerth [20] suggested that the best correlation with Cryptosporidium oocysts occurs for particles with sizes between 4 and $7 \mu \mathrm{m}$, a range also analyzed by Ribas et al. [35].

Therefore, in the current study the particle size distribution in raw water (RW) and filtered water (FW) were monitored in eight of the filtration experiments (E5-E12) using an online particle counter connected to both raw and filtered water lines of the pilot filter. Particle counts were monitored in the range of 2 to $70 \mu \mathrm{m}$ sizes. To compare the results of this study with those obtained in previous studies, for each experiment, particle sizes distribution data for the water samples were grouped in three ranges: $2-7,8-15$, and $20-70 \mu \mathrm{m}$.

The results of average particle count monitoring of filtration experiments, both for low turbidity and higher turbidity of raw water, are shown in Figure 4. Table S1, presents the particle count monitoring and removal throughout the experiments E5 to E12.
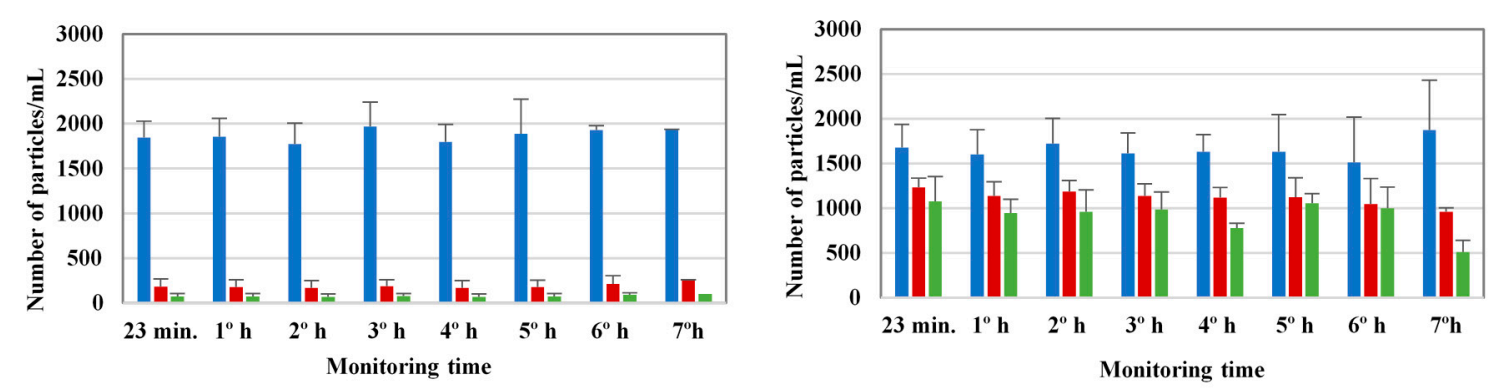

(a)
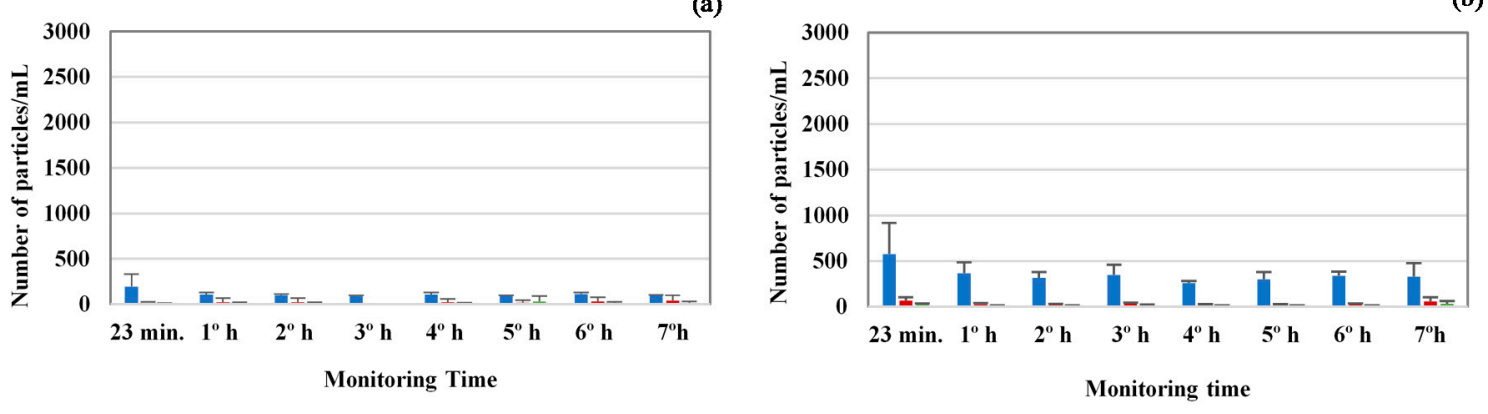

(c)

(d)

$\square \geq 2$ to $7 \mu \mathrm{m} \quad \square 8$ to $15 \mu \mathrm{m} \quad \square 20$ to $70 \mu \mathrm{m}$

Figure 4. Average particle count: $(\mathbf{a}, \mathbf{c})$ raw water and filtered water, respectively, in experiments with low turbidity raw water; $(\mathbf{b}, \mathbf{d})$ raw water and filtered water, respectively, in experiments with higher turbidity raw water. Error bars represent the standard deviation from average particle count.

In experiments conducted with low turbidity water (E5 to E9), total particle counts in influent varied from $1.45 \times 10^{3} / \mathrm{mL}$ to $3.32 \times 10^{3} / \mathrm{mL}$; in experiments with induced higher turbidity raw water (E10 to E12) total particle counts were slightly higher $\left(3.77 \times 10^{3} / \mathrm{mL}-3.99 \times 10^{3} / \mathrm{mL}\right)$. Considering the quantification of Cryptosporidium oocysts (Table 1), the contribution of oocysts to particle counts in the range $2-7 \mu \mathrm{m}$ was estimated to be between $0.02 \%$ and $0.10 \%$. Thus, the oocysts concentrations likely did not influence the behavior of particle counts in this size range in the raw water.

The difference in the total particle counts in raw water was mainly due to the increase in the number of particles in the ranges $8-15$ and $20-70 \mu \mathrm{m}$. This behavior is associated with the particle size distribution of the kaolinite suspension added to the water, whose granulometric analysis revealed that nearly $70 \%$ of kaolinite particles were greater than $7 \mu \mathrm{m}$ [36].

Concerning ripening period, a reduction in the total particle counts (TPC) in filtered water was observed. For the experiments with low turbidity water, the particle counts decreased by one to two orders of magnitude relative to the TPC of raw water, corresponding to an average removal of $1.13 \mathrm{log}$ 
units. In the experiments with high-turbidity raw water, TPC reduction was smaller, $0.56 \log$ units on average. In general, the higher particle removal was obtained for ranges 8-15 and 20-70 $\mu \mathrm{m}$ sizes.

In the experiments using higher turbidity of raw water the particle removal in the size range of 2-7 $\mu \mathrm{m}$ was on average $0.9 \log$ lower than in the experiments with low turbidity of the raw water. This behaviour may be due to the improvement of the kaolinite particles transport to the filter material surface by means of the interception and sedimentation mechanisms in the experiments conducted with higher turbidity raw water, as a function of the increase of the particle-to-collector size ratio, the particle sizes and its specific gravity. Other factor that may have favored the removal of kaolinite is associated to its structure, described by Gitis et al. [37] to be arranged in layers positively charged on their edges. Therefore, it is expected that, after coagulation at $\mathrm{pH} \sim 6.5$, destabilized kaolinite particles preserve their positive charges. Under these conditions, the electrostatic kaolinite-sand interactions may have enhanced the adhesion to the clean and negatively charged filter material surface. Once deposited, kaolinite most likely covered the collector surface preventing other particles, such as those of 2 to $7 \mu \mathrm{m}$ from Paranoá lake water, adhering to sand grains. The unfavorable interaction with kaolinite, may also have hindered the adhesion of these particles to kaolinite previously deposited onto collector surface.

Despite the reasonable removal, a significant number of particles in the range $2-7 \mu \mathrm{m}$ remained in the filter effluent throughout the filtering run, indicating the filter's vulnerability to this specific particle size range during the initial filtration period, including the filter ripening. Amirtharajah [38] highlighted that the combination of transport mechanisms through granular media filters yields a minimum net transport efficiency for particles around $1 \mu \mathrm{m}$ in size, as the efficiency of each transport mechanisms on particles removal is highly dependent of the particle size and is drastically reduced for particles that are approximately $1 \mu \mathrm{m}$.

Figure 4 shows a gradual decrease in the particle counts until the second hour of filter run, due to the repulsing forces between influent particles and the negatively charged sand surface. This period was followed by an improvement in the quality of the effluent. At the end of the run, the average log TPC removal in the experiments with low turbidity raw water was slightly higher $(1.2 \log )$ than in the experiments with higher turbidity raw water $(1.0 \mathrm{log})$, mainly due to the increase in number of particles of 2 to $7 \mu \mathrm{m}$ in the filtered water. When compared with the first five experiments (E5-E9), the average removal of particles with sizes 2 to $7 \mu \mathrm{m}$ for the last group of experiments (E10-E12) declined almost two-fold, suggesting that, similar to the initial filtering period, kaolinite particles removal may have improved as a result of the combination of the higher transport mechanisms efficiency and better kaolinite-sand interaction that preferentially attached to the sand surface in comparison with small particles formerly present in low turbidity raw water.

Figure 5 shows the removal of Cryptosporidium oocysts and particle counts for the three assessed size ranges. The values shown for both parameters correspond to the measurements recorded for the raw and filtered water at stable operation in each filtration experiment.

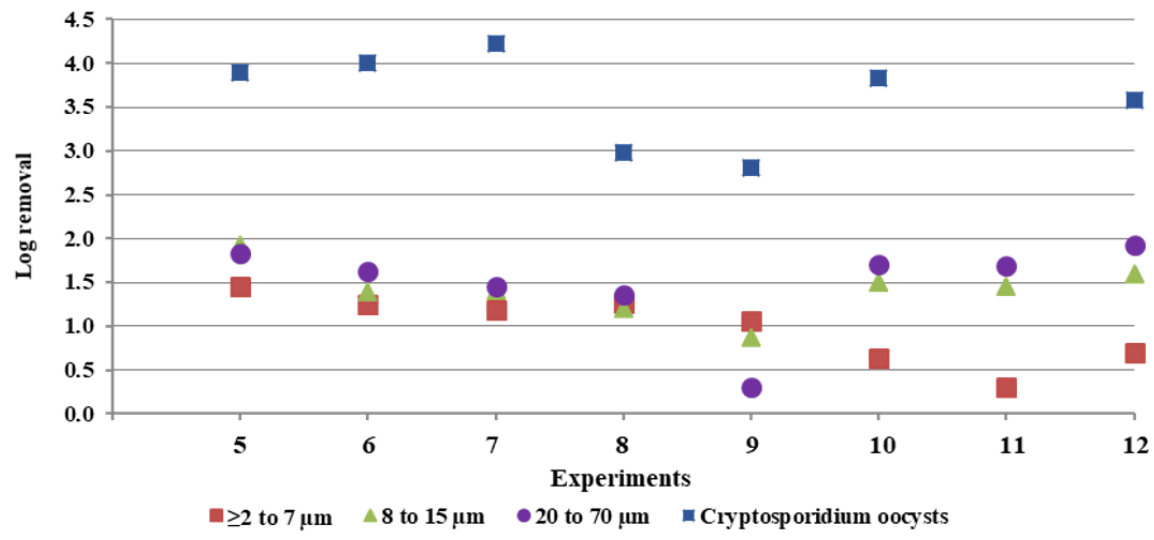

Figure 5. Removal of Cryptosporidium oocysts and particle counts in pilot-scale filtration experiments. 
In all experiments shown in Figure 5 the oocysts removals were considerably higher than particle removals. In experiments E5 to E12, on average, oocysts removal $(3.6 \mathrm{log})$ was at least 2.1 higher than particles $\log$ removals for the size ranges $2-7,8-15$, and $20-70 \mu \mathrm{m}(0.92,1.42$, and $1.49 \log$, respectively). It is also observed that the relationship between both parameters does not seem to be proportional. These observations are consistent with those reported by Edzwald et al. [39] and Huck et al. [24] in pilot conventional water treatment systems with dual-media filters operated under optimized coagulation conditions. According to Edzwald et al. [39], this behavior is most likely due to the differences among the analytical methods used to quantify both parameters, which are influenced by the small portion of oocysts in the raw water as well as the wider variety of particles characteristics such as size, shape and color. Based on the results of both studies, the authors have suggested that, under stable or optimal conditions, particle counts should be considered a conservative indicator of Cryptosporidium oocysts removal along with turbidity removal, as low levels of these parameters can be associated with good operational conditions for removal Cryptosporidium oocysts.

Remarkable differences were not observed among average oocysts removals obtained in the experiments conducted with low turbidity and higher turbidity raw water (Table 1). According to earlier studies, suspended clay particles can impact the transport and attachment of different biocolloids, including Cryptosporidium oocysts, in granular media. Gitis et al. [37] assessed the dynamics of Cryptosporidium oocysts and kaolinite particles $(0.78 \pm 0.32 \mu \mathrm{m})$ adhesion to a quartz sand surface in experiments conducted in batch reactor, and verified that after coagulation with alum for complete destabilization of suspension, oocysts adhered more effectively onto sand grains in the presence of kaolinite in the filter influent than in its absence. As a result, Cryptosporidium oocysts increased from $1 \log$ in the experiment performed with no addition of coagulant to $3.2 \log$ in the experiment with the addition of $20 \mathrm{mg} / \mathrm{L}$ of alum. According to the authors Cryptosporidium oocysts adsorbed preferentially on kaolinite particles previously deposited onto the sand grains, as the edges positively charges of kaolinite most likely functioned as electrostatic adhesives of oocysts onto the sand surface. In the conditions tested in this study, despite the kaolinite addition to the raw water in experiments E10 to E12, the kaolinite concentration might not have been high enough to influence the oocysts-sand grains interactions.

The differences in the oocyst removals observed in both studies may also be associated to the differences in the operational mode used each the experimental system. While this study was carried out on a upflow filter operating in continuous mode, the study of Gitis et al. [37] was conducted on reactors operating in batch mode. Under batch condition the hydrodynamic forces, responsible for the dynamic equilibrium between the attachment and detachment processes were suppressed, likely leading to the higher oocysts removal.

Except in experiment E9, in the remaining experiments using raw water with low turbidity (E5 to E8), the particles removal for the three evaluated sizes ranges were very close. In contrast, in experiments E10 to E12, conducted with higher turbidity raw water, particles removals in the ranges 8-15 and 20-70 $\mu \mathrm{m}$ improved, whereas the particles removal in the range 2-7 $\mu \mathrm{m}$ decreased compared to experiments with low turbidity raw water. As previously mentioned, the structural features of kaolinite may have positively influenced the kaolinite-sand interaction producing a better retention of kaolinite than small-sized particles originally present in the raw water (from Paranoá Lake).

\subsection{Correlations Analysis between Cryptosporidium Oocysts and Particle Counts}

Spearman's non-parametric correlation tests were applied to assess possible correlations between Cryptosporidium oocysts and particle counts in filtered water, as well as the correlations between removals $(\log )$ of both parameters for ripening and stable operation periods. For the correlation analysis, all the filtered water data obtained from experiments E5 to E12, in which Cryptosporidium oocysts were seeded in the filter influent and the particle counts were monitored throughout the filtration run, were considered (except experiment E11). 
The particle size ranges included in the correlation tests were $2-7,4-6,8-15$, and $20-70 \mu \mathrm{m}$, which were selected based on studies performed by Nieminski and Ongerth [20], Morse et al. [40], and Yu et al. [15].

Regarding the data obtained throughout the filtration experiments, Spearman's non-parametric tests did not show significant correlations between the levels of the parameters or between their removals (data not shown). However, when the data from ripening and stable operation periods were analysed independently, barely for ripening period the Spearman's tests showed moderately strong correlation $(r=0.70)$, significant at $90 \%$ level, between Cryptosporidium oocyst levels and particle counts for ranges $2-7$ and $4-6 \mu \mathrm{m}$, as illustrated in Table 2 .

Table 2. Spearman's correlation coefficients between Cryptosporidium oocysts, particle counts, and their removals (log) at the ripening period.

\begin{tabular}{ccccc}
\hline \multirow{2}{*}{ Oocysts } & \multicolumn{4}{c}{ Particle Size Range $(\mu \mathrm{m})$} \\
\cline { 2 - 4 } & $2-7$ & $4-6$ & $8-15$ & $20-70$ \\
\hline $\begin{array}{c}\text { Correlation } \\
\text { Coefficient }\end{array}$ & $0.70 *$ & $0.70 *$ & 0.18 & 0.46 \\
\hline \multicolumn{4}{c}{ Log Removal } \\
\hline Oocysts & \multicolumn{4}{c}{ Particle Size Range $(\mu \mathrm{m})$} \\
\cline { 2 - 4 } & $2-7$ & $4-6$ & $8-15$ & $20-70$ \\
\hline $\begin{array}{c}\text { Correlation } \\
\text { Coefficient }\end{array}$ & -0.1 & 0.30 & 0.30 \\
\hline
\end{tabular}

Cryptosporidium oocysts are reported to have sizes varying from 3 to $7 \mu \mathrm{m}[24,41]$. This size range of Cryptosporidium oocysts is considered in the Method 1623 established by the USEPA [22], aimed to recover, identify, and count Cryptosporidium oocysts and Giardia cysts. Particle counts that showed a statistically significant strong correlation with Cryptosporidium oocysts levels in filtered effluent at the ripening period comprise Cryptosporidium oocysts-sized particles (Table 2). Considering source water used as raw water in this study was low to moderate in turbidity and particles, these findings suggest a possible application of particle counts monitoring in the ranges 2-7 and 4-6 $\mu \mathrm{m}$ in the effluent of upflow filters as a complement of monitoring turbidity levels during the ripening of upflow filters, considered as critical due to the higher probability of Cryptosporidium oocysts passage.

The results of correlations tests observed herein approach to those of Yu et al. [15] that found strong correlations (Pearson) among the levels of Cryptosporidium oocysts and particle counts $(r=0.732$ and $r=0.691$, respectively) for sizes ranges $4-7 \mu \mathrm{m}$ and 7-14 $\mu \mathrm{m}$ in the effluent from pilot single medium and dual-media rapid downflow filters treating waters with low turbidity and particle levels. However, differently to the current study, such correlations were observed throughout the operation filters run.

Despite the strong correlation observed between both parameters, similarly to other studies already mentioned, the authors have proposed that monitoring the particle counts should not be used as an enough indicator of Cryptosporidium levels or its removal.

As mentioned previously, Huck et al. [24] also evaluated the relationship between removals of Cryptosporidium oocyst and particle counts $(2-150 \mu \mathrm{m})$ in three pilot scale conventional water treatment systems with double layer filters, treating raw water with low turbidity and particle counts levels (average of 5000 particles $/ \mathrm{mL}$ ). The study included the influence of the filter stages (ripening, stable or optimal operation and breakthrough) besides the operational effects such as suboptimal coagulation on the relationship between both parameters.

When statistical correlation test was applied to the data obtained in all coagulation conditions from two pilot-plants, the correlations coefficients varied from moderate to strong, suggesting that the sensitivity of particle counts may be site specific. 
Similar to the current study, no proportional relationship among removals of both parameters were found when the three pilot systems were operated at stable or optimal operation conditions, indicating that particle counts should not be considered as a quantitative indicator of Cryptosporidium removal capability when filters are operating well under stable operating conditions.

During the ripening period, although no statistical correlation tests were applied, the reduction in particles removal in relation to oocyst removal was higher than in the stable operation was observed. Sub-optimal coagulation conditions also resulted in a similar considerable average reduction both in oocyst and particle removals. Regarding the breakthrough, despite the filtration run in two pilot systems were stopped before reaching the late breakthrough, deterioration in Cryptosporidium oocysts removal was verified. Although the decrease was more significant in one of the systems, about of $3.5 \mathrm{log}$, these evidences indicate that, as in ripening, the breakthrough deserves special attention in relation to light increases in particle counts. Based on these evidences, Huck et al. [24] proposed particle counts as a useful tool for monitoring possible deterioration of filter capability for Cryptosporidium oocyst removal.

Considering a source water with low to moderate turbidity and particle counts as the raw water used in this study, the results of correlations tests corroborate with the literature, that has not consistently recommended the use of particle counts as a quantitative indicator for Cryptosporidium oocysts removal in water treatment systems operating well at stable or optimal operational conditions. However, it is possible using particle counts in the ranges 2-7 and 4-6 $\mu \mathrm{m}$ for monitoring the filtered water produced by the upflow direct filter during the ripening period, as particle counts in these size ranges seems to be sensitive to variations in the concentration of Cryptosporidium oocysts in filtered water during this vulnerable period to the Cryptosporidium oocyst passage. Based on this evidence, further studies need to be performed under other operational conditions different to those evaluated herein, such as filtration rate, composition of the filter bed and raw water quality, to confirm the relationship between particle counts and Cryptosporidium oocyst levels, not only considering the ripening and stable periods but also the breakthrough which is crucial for defining the end of filter run.

\section{Summary}

In Brazil, millions of people still receive water with only disinfection or no treatment. In this scenario, direct filtration systems, due to the lower implementation costs, play an important role in producing safe water.

Upflow direct filtration, consisting of coagulation and filtration, without the need of flocculation, became a popular option to treat water with low to moderate turbidity. In Brazilian design practice, filters used in upflow direct filtration systems are deeper, stratified, and operate with lower filtration rates compared with the ones used in downflow direct filtration.

This article assesses the removal of Cryptosporidium oocysts treating a water with low and low-moderate turbidity. The study, conducted in pilot scale, evaluated two periods within a filter cycle, ripening and stable operation, as well as correlations between filtered water values and removal of oocysts, turbidity and particle counts.

Under stable operation and optimal coagulation conditions, the average removal of Cryptosporidium oocysts was $>3.87 \mathrm{log}$, ranging from 2.80 to $>4.20 \mathrm{log}$. During the ripening period, removal of Cryptosporidium oocysts was around 1 log lower than during stable operation and this difference was statistically significant.

Removal of turbidity and particles (including those in the range of 2 to $7 \mu \mathrm{m}$ ) were lower than the removal of Cryptosporidium oocysts, suggesting that the removal of turbidity and particles may be a conservative indicator of oocysts removal.

For the specific raw water (Paranoá Lake seeded with inactivated Cryptosporidium oocysts), and treating similar flow rate, a comparison of data obtained in this study with previous results of downflow direct filtration suggested that, considering the differences in design, upflow direct filtration 
may be a more robust option regarding Cryptosporidium oocysts removal and head loss development. Further evaluation, in a broad range of conditions, is necessary to confirm these preliminary findings.

No correlation between the removal of Cryptosporidium oocysts, turbidity removal, and particle counts removal was observed, regardless of the filtration run stage. However, during ripening, a moderately strong correlation between residual values of Cryptosporidium oocysts and particles in the range of 2 to $7 \mu \mathrm{m}$ was obtained, suggesting the need for further evaluation of this behavior, particularly in the vulnerable periods within filter cycle-ripening and breakthrough.

Supplementary Materials: The following are available online at http://www.mdpi.com/2073-4441/12/5/1328/s1, Table S1. Particle counts monitoring throughout the experiments E5 to E12.

Author Contributions: All authors have read and agree to the published version of the manuscript. Conceptualization, C.C.S.B.; methodology, C.C.S.B. and Y.P.G.; formal analysis, Y.P.G.; investigation, M.F.N. and Y.P.G.; resources, C.C.S.B.; writing-original draft preparation, M.F.N. and Y.P.G.; writing-review and editing, C.C.S.B. and Y.P.G.; supervision, C.C.S.B.; project administration, C.C.S.B.; funding acquisition, C.C.S.B.

Funding: This research was funded by the Programa de Pós-Graduação em Tecnologia Ambiental e Recursos Hídricos (Environmental Technology and Water Resources Post Graduation Program, University of Brasilia).

Acknowledgments: The authors are grateful to the Brazilian National Council of Scientific and Technological Development of Brazil (CNPq) and Coordination of Superior Level Staff Improvement (CAPES) for scholarships.

Conflicts of Interest: The authors declare no conflict of interest.

\section{References}

1. Gamba, R.C.; Ciapina, E.M.P.; Espíndola, R.S.; Pacheco, A.; Pellizari, V. Detection of Cryptosporidium sp. oocysts in groundwater for human consumption in Itaquaquecetuba city, S. Paulo-Brazil. Braz. J. Microbiol. 2000, 31, 151-153. [CrossRef]

2. Bastos, R.; Heller, L.; Vieira, M.; Brito, L.; Bevilacqua, P.D.; Nascimento, L. Giardia sp. cysts and Cryptosporidium spp. oocysts dynamics in southeast Brazil: Occurrence in surface water and removal in water treatment processes. Water Supply 2004, 4, 15-22. [CrossRef]

3. Neto, R.C.; Santos, L.U.; Sato, M.I.Z.; Franco, R.M.B. Cryptosporidium spp. and Giardia spp. in the surface water supply of Campinas, Southeast Brazil. Wat. Sci. Tech. 2010, 62, 212-222. [CrossRef] [PubMed]

4. Branco, N.; Leal, D.A.G.; Franco, R. A Parasitological Survey of Natural Water Springs and Inhabitants of a Tourist City in Southeastern Brazil. Vector-Borne Zoonotic Dis. 2012, 12, 410-417. [CrossRef]

5. Franco, R.M.B.; Branco, N.; Trainotti Amaro, B.C.; Neto, R.C.; Fiuza, V.R.S. Cryptosporidium Species and Giardia Genotypes Detected in Surface Water Supply of Campinas, Southeast Brazil, by Molecular Methods. J. Vet. Med. Res. 2016, 3, 1053.

6. Grott, S.C.; Hartmann, B.; Filho, H.H.D.S.; Franco, R.; Greinert-Goulart, J. Detecção de cistos de Giardia spp. e oocistos de Cryptosporidium spp. na água bruta das estações de tratamento no município de Blumenau, SC, Brasil. Ambient. Agua-Interdiscip. J. Appl. Sci. 2016, 11, 689. [CrossRef]

7. De Araújo, R.S.; Aguiar, B.; Dropa, M.; Razzolini, M.; Sato, M.I.Z.; Lauretto, M.D.S.; Galvani, A.T.; Padula, J.A.; Matté, G.R.; Matté, M.H. Detection and molecular characterization of Cryptosporidium species and Giardia assemblages in two watersheds in the metropolitan region of São Paulo, Brazil. Environ. Sci. Pollut. Res. 2018, 25, 15191-15203. [CrossRef]

8. BRASIL Ministério da Saúde. Anexo XX da Portaria de Consolidação no 5 de 28 de setembro de 2017: Dispõe sobre os procedimentos de controle e de vigilância da qualidade da água para consumo humano e seu padrão de potabilidade. In Procedures for the Control and Surveillance of Water Quality for Human Consumption and Its Potability Standards; Ministry of Health: Brasília, Brazil, 2017. (In Portuguese)

9. Bitton, G. Microbiology of Drinking Water; Wiley: Hoboken, NJ, USA, 2014; p. 312.

10. Di Bernardo, L.; Mendes, C.G.N.; Brandão, C.C.S.; Sens, M.L.; Pádua, V.L. Tratamento de água para abastecimento por filtração direta (Projeto Prosab). In Drinking Water Treatment by Direct Filtration; ABES-RIMA: Rio de Janeiro, Brazil, 2003; p. 498. (In Portuguese)

11. IBGE-Instituto Brasileiro de Geografia e Estatística. Pesquisa Nacional de Saneamento Básico. In National Survey on Drinking Water and Sanitation; Governo Federal: Brasília, Brasil, 2008. 
12. Ongerth, J.E.; Pecoraro, J.P. Removing Cryptosporidium using multimedia filters. J. Am. Water Works Assoc. 1995, 87, 83-89. [CrossRef]

13. Emelko, M. Removal of viable and inactivated Cryptosporidium by dual- and tri-media filtration. Water Res. 2003, 37, 2998-3008. [CrossRef]

14. Emelko, M.; Huck, P.M.; Douglas, I.P. Cryptosporidium and microsphere removal during late in-cycle filtration. J. Am. Water Works Assoc. 2003, 95, 173-182. [CrossRef]

15. Yu, M.; Ahn, S.; Chung, S.; Noh, S.; Park, J.; Rhim, Y.; Jheong, W.; Chung, H. Evaluation of the rapid filtration system with particle size distribution and Cryptosporidium in different operating conditions. Water Supply 2006, 6, 129-139. [CrossRef]

16. Fernandes, N.M.G. Influência do pH de coagulação e dosagem de sulfato de alumínio na remoção de oocistos de Cryptosporidium por Filtração Direta Descendente [Influence of coagulation $\mathrm{pH}$ and aluminium sulphate dosage on the removal of Cryptosporidium oocysts by downflow direct filtration]. Dissertation. In Master in Environmental Technology and Water Resources; Universidade de Brasília: Brasília, Brazil, 2007; 144 p. (In Portuguese)

17. Gitis, V. Rapid sand filtration of Cryptosporidium parvum: Effects of media depth and coagulation. Water Supply 2008, 8, 129-134. [CrossRef]

18. Brown, T.J.; Emelko, M. Chitosan and metal salt coagulant impacts on Cryptosporidium and microsphere removal by filtration. Water Res. 2009, 43, 331-338. [CrossRef]

19. ABNT-Associação Brasileira de Noramas Técnicas. NBR 12216/1992 Projeto de estação de tratamento de água para abastecimento público. In Public Water Supply Systems-Designs of Water Treatment Works-Procedure; ABNT: Rio de Janeiro, Brazil, 1992; p. 17. (In Portuguese)

20. Nieminski, E.C.; Ongerth, J.E. Removing Giardia and Cryptosporidium by conventional treatment and direct filtration. J. Am. Water Work. Assoc. 1995, 87, 96-106. [CrossRef]

21. Sens, M.L.; Dalsasso, R.L.; Melo Filho, L.C.; Mondardo, R.I.; Simioni, D. Relatório de Atividades PROSAB-Edital 3-Tema I. In Report of Activities; Uinversidade Federal de Santa Catarina: Santa Catarina, Brazil, 2002; Personal Communication.

22. USEPA. Method 1623: Cryptosporidium and Giardia in Water Using Filtration/IMS/FA; U.S. Environmental Protection Agency: Washington, DC, USA, 2005.

23. Hall, T.; Pressdee, J.; Gregory, R.; Murray, K. Cryptosporidium removal during water treatment using dissolved air flotation. Water Sci. Tech. 1995, 31, 125-135. [CrossRef]

24. Huck, P.; Coffey, B.; Anderson, W.B.; Emelko, M.; Maurizio, D.; Slawson, R.; Douglas, I.; Jasim, S.; O'Melia, C. Using turbidity and particle counts to monitor Cryptosporidium removals by filters. Water Supply 2002, 2, 65-71. [CrossRef]

25. Huck, P.M.; Coffey, B.M.; Emelko, M.B.; Maurizio, D.D.; Slawson, R.M.; Anderson, W.B.; Oever, J.V.D.; Douglas, A.P.; O'Melia, C.R. Effects of Filter Operation on Cryptosporidium Removal Microbial Pathogens. J. Am. Water Works Assoc. 2002, 94, 97-111. [CrossRef]

26. Emelko, M.; Huck, P.M.; Coffey, B.M. A review of Cryptosporidium removal by granular media filtration. J. Am. Water Works Assoc. 2005, 97, 101-115. [CrossRef]

27. O'Melia, C.R.; Ali, W. The Role of Retained Particles in Deep Bed Filtration. Ninth Int. Conf. Water Pollut. Res. 1979, 10, 167-182. [CrossRef]

28. USEPA. National Primary Drinking Water Regulations: Electronic Code of Federal Regulations. Federal Register-Part II-40CFR, Parts 9, 141 and 142. Long Term 2 Enhanced Surface Water Treatment Rule; Final Rule; U.S. Environmental Protection Agency: Washington, DC, USA, 2006.

29. Xagoraraki, I.; Harrington, G.; Assavasilavasukul, P.; Standridge, J.H. Removal of Emerging Waterborne Pathogens and Pathogen Indicators by Pilot-Scale Conventional Treatment. J. Am. Water Works Assoc. 2004, 96, 102-113. [CrossRef]

30. Swertfeger, J.; Metz, D.H.; Demarco, J.; Braghetta, A.; Jacangelo, J.G. Effect of filter media on cyst and oocyst removal. J. Am. Water Works Assoc. 1999, 91, 90-100. [CrossRef]

31. Dugan, N.R.; Fox, K.R.; Owens, J.H.; Miltner, R.J. Controlling Cryptosporidium Oocysts Using Conventional Treatment. J. Am. Water Works Assoc. 2001, 93, 64-76. [CrossRef] 
32. Fagundes, A.P. Remoção de oocistos de Cryptosporidium por Filtração Direta-Influência de alguns aspectos operacionais [Removal of Cryptosporidium oocysts by direct filtration-Influence of some operational aspects]. Dissertação. In Master in Environmental Technology and Water Resources; Universidade de Brasília: Brasília, Brazil, 2006; p. 143. (In Portuguese)

33. Liu, L.; Wang, Y.; Craik, S.; James, W.; Shu, Z.; Narain, R.; Liu, Y. Removal of Cryptosporidium surrogates in drinking water direct filtration. Colloids Surf. B Biointerfaces 2019, 181, 499-505. [CrossRef] [PubMed]

34. Lechevallier, M.W.; Norton, W.D. Examining Relationships between Particle Counts and Giardia, Cryptosporidium, and Turbidity. J. Am. Water Works Assoc. 1992, 84, 54-60. [CrossRef]

35. Ribas, F.; Bernal, A.; Perramon, J. Elimination of Giardia cysts, Cryptosporidium oocysts, turbidity and particles in a drinking water treatment plant with clarification and double filtration. Water Sci. Technol. 2000, 41, 203-211. [CrossRef]

36. Mendez, I.M.R. Remoção de microesferas de poliestireno, em substituição a oocistos de Crypstosporidium, por filtração direta ascendente no tratamento de água usando o coagulante quitosana [Microspheres of polystyrene removal, in substitution of Crypstosporidium oocysts, by up-flow in-line filtration in water treatment, using chitosan coagulant]. Dissertation. In Master in Environmental Technology and Water Resources; Universidade de Brasília: Brasilia, Brazil, 2014; p. 123. (In Portuguese)

37. Gitis, V.; Haught, R.C.; Clark, R.M.; Rothenberg, G. Assessing the removal of inorganic colloids and Cryptosporidium parvum from drinking water. J. Environ. Monit. 2002, 4, 244-248. [CrossRef]

38. Amirtharjah, A. Some Theoretical and Conceptual Views of Filtration. JAWWA 1988, 80, 36-46. [CrossRef]

39. Edzwald, J.K.; Tobiason, J.; Parento, L.M.; Kelley, M.B.; Kaminski, G.; Dunn, H.J.; Galant, P.B. Giardia and Cryptosporidium Removals by clarification and filtration under challenge conditions. J. Am. Water Works Assoc. 2000, 92, 70-84. [CrossRef]

40. Morse, A.; Wilson, R.; Hüll, A.; Simms, J. Monitoring for Cryptosporidium risk: Do particle counters help? Water Supply 2002, 2, 171-180. [CrossRef]

41. Tufenkji, N.; Miller, G.F.; Ryan, J.N.; Harvey, R.; Elimelech, M. Transport of Cryptosporidium Oocysts in Porous Media: Role of Straining and Physicochemical Filtrationt. Environ. Sci. Technol. 2004, 38, 5932-5938. [CrossRef]

(C) 2020 by the authors. Licensee MDPI, Basel, Switzerland. This article is an open access article distributed under the terms and conditions of the Creative Commons Attribution (CC BY) license (http://creativecommons.org/licenses/by/4.0/). 